\title{
"LEITORAS": \\ GÊNERO, RAÇA, IMAGEM E DISCURSO \\ EM O MENELIK (SÃO PAULO, 1915-1916)
}

Giovana Xavier da Conceição Côrtes"

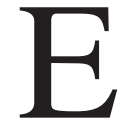

ste artigo tem como objetivo analisar as representações que os jornalistas do Menelik faziam das mulheres negras, examinando em que medida elas podem ajudar a reconstituir a participação feminina na folha. ${ }^{1}$ Para tal, utilizamos como fontes os dois exemplares que compõem a sua coleção ${ }^{2}$, ambos publicados na cidade de São Paulo em outubro de 1915 e janeiro de $1916 .{ }^{3}$

Ao considerar o ainda tímido investimento historiográfico em estudos sobre as mulheres no pós-emancipação ${ }^{4}$, a metodologia adota-

Professora substituta de Didática Especial e Prática de Ensino de História na UFRJ.

1 Agradeço os valiosos comentários e sugestões feitos por Sidney Chalhoub, Robert Slenes, Silvia Lara, Álvaro Nascimento, Marc Hertzman, Paulina Alberto e Micol Seigel durante a escrita do texto.

2 Ao comentar sobre os diferentes títulos da imprensa negra, José Correia Leite é categórico ao elencar $O$ Menelik na lista dos periódicos que circularam por mais tempo em São Paulo: "houve jornais que não duraram mais que 2 ou 3 números. Outros tinham vida longa, como por exemplo O Kosmos, O Menelick, O Alfinete". Este relato de um contemporâneo sobre periódicos com "vida longa" somado à inexistência de outras edições nos acervos pesquisados leva a crer que diversos números do jornal "dedicado aos homens de cor" foram extraviados. José Correia Leite e Cuti, ... E disse o velho militante José Correia Leite. São Paulo: Noovha América, 2007, p. 47.

3 A pesquisa foi realizada na coleção "Jornais da Raça Negra", Rolo PR- 00798-00834, Seção de Periódicos (Catálogo de Microfilmados), Fundação Biblioteca Nacional. Doravante, FBNCPM. Além disso, parte dos títulos também podem ser encontrados no Arquivo Edgard Leuenroth (AEL-Unicamp) e no Instituto de Estudos Brasileiros (IEB-USP).

4 Trabalho que considera a trajetória das mulheres negras no pós-emancipação está em: Silvana Santiago, Tal Conceição, Conceição de Tal. Classe, gênero e raça no cotidiano de mulheres pobres no Rio de Janeiro nas primeiras décadas republicanas (Dissertação de Mestrado, Univer- 
da baseou-se na leitura minuciosa das referidas edições e na posterior seleção e análise dos textos nos quais as personagens negras foram de, alguma forma, retratadas. A documentação em questão foi cruzada com alguns textos da revista feminina A Mensageira (1897-1900), ${ }^{5}$ assim como com a produção temática ${ }^{6}$ para que também observássemos de que forma as identidades das mulheres "de cor" - como se dizia à época - se aproximavam ou distanciavam das idealizações femininas "universais", relacionadas a temas como pureza, honra e moralidade.

Como veremos, as mulheres ocuparam parte considerável das páginas do Menelik. Digo isso porque, além de terem sido retratadas em poesias, contos, notas, avisos etc., foram ainda agraciadas com um concurso exclusivamente dedicado à "belleza feminina" e, por vezes, lembradas como colaboradoras. Mesmo que nos momentos mais emblemáticos os redatores se fizessem valer de categorias femininas genéricas, tais como "mães", "leitoras", "candidatas", "senhoritas", "senhoras" - o que, aliás, dificulta o trabalho de identificação precisa dos sujeitos - , creio que tais aparições, por si só, já são suficientes para, no mínimo, questionar o "meio negro" letrado como universo essencialmente masculino.

sidade Estadual de Campinas, 2006). Embora não focalizem as análises nas mulheres negras, apontamentos a respeito da articulação entre gênero e raça no mundo livre podem ser vistos em: Rachel Soihet, Condição feminina e formas de violência: mulheres pobres e ordem urbana, 1890-1920, Rio de Janeiro: Forense Universitária, 1985; Martha Abreu, Meninas perdidas: os populares e o cotidiano do amor no Rio de Janeiro da Belle Époque, Rio de Janeiro: Paz e Terra, 1989; Joana Maria Pedro, Mulheres honestas, mulheres faladas: uma questão de classe, Florianópolis: Editora da UFSC, 1994; Sueann Caulfield, Em defesa da honra: moralidade, modernidade e nação no Rio de Janeiro (1918-1940), Campinas: Edunicamp, 2000. FBN-Cátalogo de Periódicos Digitalizados (doravante CPD), 1897-1900.

6 Ver, dentre outros: Anna Luiza Martins, "A produção de uma nova mulher: revistas femininas", in Anna Martins, Revista em revista: imagens e práticas culturais em tempos da república, São Paulo, 1890-1922, São Paulo: Edusp / Fapesp, 2001, pp. 371-86.

7 O conceito de "meio negro" aparece nos depoimentos de José Correia Leite em diversas ocasiões em que o militante se refere aos participantes da imprensa negra assim como aos frequentadores e membros de clubes, grêmios e demais associações de cor da cidade de São Paulo na Primeira República. Ao rememorar sua entrada no "meio negro" como frequentador dos bailes promovidos pelo "Elite Flor da Liberdade", Correia Leite deixou registrado: "estou perdendo tempo com esses italianos. Eu tenho uma sociedade que é minha, meu povo, minha gente. Fui procurar e encontrei gente conhecida. Justamente um que foi uma espécie de irmão de criação para mim. Ele se chamava Manoelzinho e foi quem me apresentou outras pessoas. Assim, comecei a participar do meio negro que até então eu não conhecia”. Tudo indica que a recorrência da categoria "meio negro" nos estudos de Florestan Fernandes e Roger Bastide deve-se à importância dos depoimentos de Correia Leite nas suas pesquisas. O trabalho pioneiro - 
As tensões entre o masculino e o feminino, com a sobreposição do primeiro em relação ao segundo, foram elementos que atravessaram a formação da imprensa negra, assim como as práticas de seus intelectuais e entusiastas ao longo do século XX em diferentes territórios. ${ }^{8}$ Ao discutir o cabelo "afro" enquanto uma política de contracultura à dominação branca nos EUA dos anos 1960, por exemplo, Robin Kelley demonstra o quanto tal história vem sendo contada de um ponto de vista "falocêntrico", , embora "mulheres da raça", como Madame C. J. Walker, Anne Poppe Turnbo-Malone e tantas outras "culturistas", tenham sido centrais para a constituição de "políticas do cabelo" 10 relacionadas ao levantamento moral da "raça negra" desde pelo menos os anos 1900. ${ }^{11}$

Em contraponto à perspectiva "falocêntrica" das políticas negras, a pesquisa do Menelik indica a existência de nuances e conflitos entre "presença" e "participação" femininas. Assim, interessada em conectar as questões de gênero e raça ao "problema da liberdade" 12 nas Américas, algumas perguntas, tecidas em diálogo com a historiografia sobre gênero e história das mulheres ${ }^{13}$, tornam-se providenciais. Como o es-

"Movimentos Sociais no Meio Negro" - assinado por Renato Jardim Moreira com a "colaboração" de Correia Leite também indica que a autoria do conceito é tributária das interpretações de Leite sobre essa parcela da população de cor paulistana. A respeito do "meio negro" e da trajetória de José Correia Leite ver: José Correia Leite e Cuti, ... E disse o velho militante José Correia Leite: depoimentos e artigos, São Paulo: Secretaria Municipal de Cultura, 1992, p. 27.

8 Sobre história transnacional, diáspora e intelectuais negros ver: Brent Hayes Edwards, The Practice of Diaspora: Literature, Translation, and the Rise of Black Nationalism, Cambridge: Harvard University Press, 2003; Zita Nunes, Cannibal Democracy: Race and Representation in the Literature of the Americas, Minneapolis / Londres: University of Minnesota Press, 2008.

9 Robin Kelley, "Nap Time: Historicizing the Afro", Fashion Theory: The Journal of Dress, Body \& Culture, v.1, n. 4 (1997), pp. 339-51.

${ }_{10}$ Kelley, "Nap Time, pp. 339-51.

11 A respeito das articulações entre gênero, raça e cosmética na imprensa negra pós-emancipação nos EUA ver: Giovana Xavier, Brancas de almas negras? Beleza, racialização e cosmética na imprensa negra pós-emancipação (EUA, 1890-1930) (Tese de Doutorado, Unicamp, 2012).

12 Thomas C. Holt, The Problem of Freedom: Race, Labor, and Politics in Jamaica and Britain, 1832-1938, Baltimore / Londres, The Johns Hopkins University Press, 1992.

13 A respeito das relações entre gênero, feminino e relações de poder ver: Joann Scott. "Gênero: uma categoria útil de análise", Educação e Realidade: Gênero e Educação, v.15, n.2 (1990), pp. 71-99. Uma importante discussão sobre saberes masculinos e representações femininas está em: Rachel Soihet, "Violência simbólica: saberes masculinos e representações femininas", Revista de Estudos Feministas, v. 1, n. 5 (1997). Disponível em: http:// www.periodicos.ufsc.br/index.php/ref/article/view/12558/11703 Acesso: 11/07/2011. 
tudo de representações femininas feitas por homens contribui para reconstituição da agência das mulheres de cor na imprensa negra? Por que os jornalistas se preocupavam em sempre retratar o feminino? Uma vez que seus nomes não aparecem nas matérias assinadas e nas listas de cargos diretivos, quais seriam as formas de participação das mulheres no jornal? Como identificá-las? De que maneiras as imagens construídas a respeito de seus corpos e comportamentos contribuíam para os projetos de integração da população de cor no mundo livre? E não menos importante: afinal, quem eram essas personagens? Mas antes de tentar responder a estas perguntas, vamos conhecer um pouco da história e da estrutura da publicação.

\section{O Menelik e sua "classe"}

Agora cremos que o nosso jornal há de ter um futuro brilhante porque contamos com a aprovação geral da "classe". ${ }^{14}$

Depois de uma semana de trabalho, Deocleciano Nascimento, Geraldino de Souza, Juvenal de Padua Mello e outros oito companheiros abriram mão das prerrogativas do dia santo e escolheram o terceiro domingo do mês de julho de 1915 para mais trabalho. ${ }^{15}$ À ocasião, o grupo se reuniu e acertou os ponteiros de assunto que julgava importante para a "classe": o surgimento de mais um jornal de cor na grande São Paulo. Certos do que pretendiam, os futuros jornalistas assim batizaram seu rebento: $O$ Menelik: Orgam mensal, noticioso, literário e crítico dedicado aos homens de cor. ${ }^{16}$

14 FBN-CPM, "O Menelik", O Menelik, São Paulo, 17 de outubro de 1915, anno 1, n. 1, p. 1.

15 FBN-CPM, "O Menelik", O Menelik, 17 de outubro de 1915, anno 1, n. 1, p. 1.

${ }^{16}$ No número de estreia do jornal a grafia do título é Menelik. Na edição de janeiro de 1916, passa para Menelick. Neste artigo, ao mencionar o jornal optei pela grafia da primeira edição, inclusive por considerar que a forma de escrita Menelik relaciona-se com possíveis influências de intelectuais afro-americanos. Discussões sobre as conexões entre jornalistas negros brasileiros e norte-americanos encontram-se em: Amilcar Araújo Pereira,"O Mundo Negro": a constituição do movimento negro contemporâneo no Brasil (1970-2001) (Tese de Doutorado, Universidade Federal Fluminense, 2010); Micol Seigel, "The Point of Comparison: Transnational Racial Construction, Brazil and the United States, 1918-1933” (Tese de Doutorado, New York University, 2001); Paulina Alberto, Terms of Inclusion: Black Intellectuals and the Politics of Belonging in Twentieth-Century Brazil, Chapel Hill: University of North Carolina Press, 2011. 
Apesar de terem se encontrado em julho, na casa do "Snr. Deocleciano Nascimento", situada à "rua da Graça, n. 207", o primeiro número foi publicado apenas três meses depois, em 17 de outubro de 1915.

$\mathrm{O}$ expediente esclarece que Deocleciano Nascimento era o "redactor-chefe" e Geraldino do Amaral, o "redactor-geral", e que o periódico contava ainda com Reginaldo Maximo Gonçalves ("Presidente"), Octaviano Ferraz ("Secretário"), Avelino Paiva, Marcelino Cruz, Cabo Manoel Domingos, José Felipe ("Representantes") e Theophilo Gonçalves de Freitas, José Luiz Sampaio e José Paulino ("Reporters"). Além destes, Juvenal de Padua Mello, João Benedicto e Aristides Alves da Costa também foram lembrados como participantes da referida reunião do "corrente anno" na casa do presidente da folha. ${ }^{17}$

No subtítulo, a folha apresentava-se como Orgam mensal, noticioso, literário e crítico dedicado aos homens de cor. Dispunha de quatro páginas, tendo cada uma quatro colunas, seguindo o formato tablóide comum à época. Sobre as tiragens inexistem informações nas duas edições consultadas. Já sobre os preços, se sabe que a assinatura custava $1 \$ 500$ réis por semestre. Nesse sentido, a organização do jornal se mostra das mais cortezes com seus futuros leitores: "este jornal será distribuído a todo aquele que quiser ser seu admirador. Basta só nos enviar a direção que 'O Menelik' vai lhe ter nas mãos". Ao mesmo tempo, os redatores deixavam claro que, uma vez informada a tal "direção", o compromisso estava selado: "ahi em diante será considerado como assignante [sic] concorrendo para tal fim a insignificante quantia de $1 \$ 500$ réis por seis mezes". ${ }^{18}$ A leitura atenta do editorial de estreia sugere ainda que o grupo (ao menos parte de seus membros) já tivesse alguma experiência associativa prévia, que pode ser sentida pela maneira com que a reunião é descrita:

O Snr. Deocleciano Nascimento aproveitando aquella opportunidade convocou uma sessão, convidando o Snr. Juvenal de Paula Mello, para servir de secretario, e pedindo a palavra expôz o motivo da mesma, a qual tratava-se da fundação deste jornal. ${ }^{19}$

${ }^{17}$ FBN-CPM, "Propriedade", O Menelik, 17 de outubro de 1915, anno 1, n. 1, p. 1.

18 FBN-CPM, "Avisos Importantes", O Menelik, 17 de outubro de 1915, anno 1, n. 1, p. 2.

19 FBN-CPM, "O Menelik", O Menelik, 17 de outubro de 1915, anno 1, n. 1, p. 1. 
Ao considerar a circulação de personagens no interior do meio negro, cabe enfatizar que Deocleciano Nascimento foi um dos jornalistas que mais se destacou na imprensa de cor paulista da Primeira República, tendo participado de diferentes jornais e sendo reconhecido por seus pares como uma estimada figura. Não por acaso, ele é homenageado, em 1925, pelo notório Clarim da Alvorada, que, passada uma década do surgimento do Menelik, publicava: "completou mais um aniversario a 7 do corrente o Snr. Deocleciano Nascimento, poeta e guarda-livros, nosso presado [sic] leitor e amigo, às felicitações recebidas juntamos as nossas, desejando-lhe longa vida e felicidade". ${ }^{20}$

Mas voltando ao Menelik, em termos da estrutura, o "jornalsinho" ${ }^{21}$ apresentava uma organização bem delimitada. No centro da primeira página publicava poesias e colunas distintas. Naquela denominada "Notas", eram divulgadas reuniões como a da "Sociedade Jornalística de 'O Menelik', marcada para o dia 24 do "corrente mez". ${ }^{22}$ No espaço apareciam também informações sobre novas associações negras em São Paulo. Era o caso, por exemplo, do Centro Recreativo Estrella do Oriente, no "districto do Bom Retiro". Existia também uma coluna para "Avisos Importantes", na qual, dentre outras, comentava-se a suspensão temporária do jornal, que, após outubro, reapareceria apenas em janeiro de 1916.

Outra coluna, que conheceremos melhor mais adiante, era aquela denominada "Idéias Parafuzadas", na qual Duque convocava certos senhores, senhoras e senhoritas a contribuir com $O$ Menelik, deixando a timidez de lado. Já a "Caixa-Balaio" assinada por D'eoclé (provavelmente Deocleciano do Nascimento) parece tratar-se de um espaço para aqueles já considerados colaboradores do jornal. Nela, as pessoas recebem cumprimentos por textos publicados e outros, como o Snr. Roque R., são cobrados quanto ao atraso no envio de material. Numa perspectiva comparada entre as duas colunas, é possível cogitar que "Idéias Parafuzadas" fosse voltada para seduzir colaboradores com potencial,

${ }^{20}$ FBN-CPM, O Clarim da Alvorada, São Paulo, 27 de setembro de 1925, ano II, n. 15, p. 2.

21 “(...) como resa o cabeçalho deste jornalsinho (...)". FBN-CPM, "Destino", O Menelik, 17 de outubro de 1915, anno 1, n. 1, p. 1.

22 FBN-CPM, "Notas", O Menelik, 17 de outubro de 1915, anno 1, n. 1, p. 2. 
como Izaurinha e Brasilia, duas "intelligentes e distinctas normalistas", ${ }^{23}$ e "Caixa-Balaio" se configurasse no espaço que o jornal usava para se comunicar com colaboradores efetivos, conforme D. Leopoldina que, aliás, já enviara seus versos.

Compunham o jornal, ainda, as colunas "Pelos Salões" e "Vida Social". Na primeira, eram retratados eventos como o baile do São Paulo Recreativo Club, que, animadíssimo, começou à meia-noite e estendeu-se até as seis de manhã. ${ }^{24}$ Já em "Vida Social", como o próprio nome sugere, a classe era informada sobre nascimentos, aniversários, casamentos e problemas de saúde que afetavam seus membros. Ao ler o segundo número, percebe-se que este também era o lugar reservado às notícias sobre "necrologia" ou "passamento", como o ocorrido com a "interessante menina Conceição, saudosa filhinha do Snr. Mario Nogueira do Espírito Santo e sobrinha do Snr. Reginaldo Maximo Gonçalves", que como sabemos (pelo editorial do número de estreia) era o presidente do jornal. ${ }^{25}$

No mesmo número que informava o "passamento", além das colunas supracitadas (à exceção de "Idéias Parafuzadas"), encontramos a nossa conhecida "Caixa-Balaio", rebatizada de "A caixa e o balaio" e "Na Berlinda", inexistente na edição inaugural. Na última, B. Pereira elogia “A. M. Cruz porque é sincero" e implica com "A. A. Da Costa porque é pedante". "Conquistador", "apaixonado", "estudioso", "poeta", "aguia" [sic] e "smart" [sic] também foram adjetivos empregados por "A calceira, B. Pereira" para se referir aos colegas da classe. ${ }^{26}$

Ao tentar compreender a noção de pertencimento a uma comunidade que movia os integrantes do Menelik, podemos perceber que o jornal primava por apresentar uma relação de familiaridade entre si e os personagens que citava em diferentes seções. Assim, ficamos sabendo da "senhorinha de olhar vivo que enthusiasma a si própria", ${ }^{27}$ de D.

\footnotetext{
FBN-CPM, "Idéias Parafuzadas", O Menelik, 17 de outubro de 1915, anno 1, n. 1, p. 3.

FBN-CPM, "Pelos Salões", O Menelik, 17 de outubro de 1915, anno 1, n. 1, p. 3.

${ }^{25}$ FBN-CPM, "Vida Social/Necrologia", O Menelick, 1 de janeiro de 1916, anno 1, n. 3, p. 3.

${ }^{26}$ FBN-CPM, B. Pereira, "Na Berlinda", O Menelick, 1 de janeiro de 1916, anno 1, n. 3, p. 3.

27 FBN-CPM, Geraldino Souza, "No meio de muitas...", O Menelik, 15 de outubro de 1916, anno 1, n. 1, p. 2.
} 
Leopoldina e suas "composições" 28 e de aniversariantes dos meses de agosto e setembro, tais como o próprio Deocleciano Nascimento, "ideador desta folha". ${ }^{29}$ Estas, assim como outras partes, reforçam a proposição de uma comunidade de cor letrada, que dividida entre produtores, leitores e conhecedores do jornal auto-intitulava-se "classe". ${ }^{30}$

Dentro de uma perspectiva classista, a menção a diversas associações de cor também corrobora a ideia de familiaridade entre uma comunidade negra que, aliás, transcende as páginas do jornal. ${ }^{31}$ Os redatores fazem questão de se apresentar à "Federação Paulista dos Homens de Cor" de Campinas na coluna "Pelos salões", onde também são comentados o São Paulo Recreativo Clube e seus "deciplinados amadores" $\left[\right.$ sic.$^{32}$ Além disso, em "Notas", aparece o "club de dansa" Centro Independente do Bom Retiro, o Centro Recreativo Estrella do Oriente, um segundo clube dançante, e o Sul Africano Foot Ball Club. ${ }^{33} \mathrm{O}$ aparecimento de quatro associações em duas colunas distintas - "Pelos salões" e "Notas" - nos leva a refletir sobre a lógica interna do título. Enquanto a primeira se dedicava a parabenizar associações que já possuíam algum tipo de reconhecimento entre os homens de cor: "qual é a creatura que não conhece este club dansante [São Paulo Recreativo Club], pois elle é tão conhecido entre nós que amamos a vida social", ${ }^{34}$ a segunda ("Notas") se incumbia de apresentar as novidades surgidas no mundo do associativismo negro:

Centro Independente Bom Retiro: com a denominação acima surgiu mais um club de dansa edificado pelos homens de cor. Ao Centro Independente Bom Retiro, O Menelik almeja um futuro brilhante". ${ }^{35}$

${ }^{28}$ FBN-CPM, D'eocle. "Caixa-Balaio", O Menelik, 15 de outubro de 1916, anno 1, n. 1, p. 3.

29 FBN-CPM, "Vida Social", O Menelik, 15 de outubro de 1916, anno 1, n. 1, p. 3.

30 Para entender melhor os sentidos de classe nos escritos da imprensa negra, ver, por exemplo: S. O. "O Baluarte". FBN-CPM, O Baluarte: orgam official do "Centro Litterario dos Homens de Cor - DEDICADO A DEFEZA DA CLASSE". Campinas, 15 de janeiro de 1904, anno 1, n. 3, p. 1 e FBN-CPM, "Cinco Anos de Clarinadas", Clarim d'Alvorada: legítimo orgão da mocidade negra, São Paulo, 6 de janeiro de 1929, p. 1.

31 Sobre as formas de associativismo na Primeira República ver, dentre outros: Claudio H. M. Batalha, "Cultura associativa no Rio de Janeiro da Primeira República", in Claudio Batalha; Fernando Teixeira da Silva; Alexandre Fortes (orgs.), Culturas de Classe (Campinas, Edunicamp, 2004), pp. 95-119.

32 FBN-CPM, "Pelos salões", O Menelik, 15 de outubro de 1915, anno 1, n. 1, p. 3.

33 FBN-CPM, "Notas", O Menelik, 15 de outubro de 1915, anno 1, n. 1, p. 2.

${ }^{34}$ FBN-CPM, "Pelos salões", O Menelik, 17 de outubro de 1915, anno 1, n. 1, p. 3.

35 FBN-CPM, "Notas", O Menelik, 17 de outubro de 1915, anno 1, n. 1, p. 2. 
Centro Recreativo Estrella do Oriente: mais um club dansante surgiu no districto do Bom Retiro". ${ }^{36}$

Dentro de uma história social do pós-emancipação, cabe enfatizar que "classe dos homens de cor" era a forma pela qual os jornalistas da imprensa negra geralmente se auto-intitulavam. $\mathrm{O}$ intento de preparar a população de cor para a vida livre, através da educação e conscientização sobre a importância do trabalho, somado à recorrência da terminologia acima nos subtítulos e textos de diversos periódicos indicam que "classe" era acionada como uma categoria que distinguia os intelectuais (sempre representados como trabalhadores instruídos, elegantes e críticos) da maior parte da gente negra.

Além do sentido elitista, "classe" também era usada para frisar formas de associativismo de cor outras que não os jornais, tais como clubes recreativos, grêmios dramáticos e literários, federações etc. No caso específico da comunidade de $O$ Menelik, apesar das hierarquias, conflitos e ambiguidades disparadas pelas questões de gênero, o fato de serem homens e mulheres negros, que, independente do seu grau de instrução, vivenciavam na pele o preconceito, fazia com que se sentissem pertencentes à "classe de cor". Para tal grupo, "classe" referia-se ao reconhecimento de uma origem racial que sabiam ser determinante para o "preconceito de cor" vivenciado no mercado de trabalho, no lazer e no dia a dia. Assim, ao ter em mente que, de acordo com Thompson, "a classe acontece quando alguns homens, como resultado de experiências comuns (herdadas ou partilhadas), sentem e articulam a identidade de seus interesses entre si, e contra outros homens cujos interesses diferem (e geralmente se opõem) dos seus", a criação da referida "classe de cor" representou uma das formas de lutar pela cidadania plena para os negros no pós-emancipação. ${ }^{37}$

Agora que já conhecemos um pouco mais dos personagens, do conteúdo e da lógica do Menelik, convido o leitor a iniciar o mergulho

${ }^{36}$ FBN-CPM, "Notas", O Menelik, 17 de outubro de 1915, anno 1, n. 1, p. 2.

37 Discussões essenciais sobre as relações entre classe e história estão em Edward P. Thompson, A formação da classe operária inglesa. A árvore da liberdade, Rio de Janeiro, Paz e Terra, 1987, v. I, p. 10. 
no universo das suas misteriosas "leitoras", lançando mão, para tal, de alguns cruzamentos com tipologias e debates presentes no periodismo feminino da Primeira República.

\section{Fabricando novas mulheres negras: beleza, raça e imagem no Menelik}

Em 1916, o Menelik divulgava seu intento de homenagear as mulheres de cor através de um evento que desse vivas à sua beleza:

Abrimos com o presente número um concurso de beleza feminina, cujo concurso será em duas tiragens distribuídas nas seguintes formas: na primeira tiragem, a partir da próxima vindora, daremos uma demonstração geral de todas aquelas que mereceram votos e, na segunda, o resultado final do concurso. Aquela que bater o "record" ornamentará com o seu retrato a primeira página de nosso jornal, caso consinta que nós assim procedemos. N.B. - O concurso é bem entendido, entre a "classe" e os votos devem ser dados pelos homens que forem assinantes, enchendo para este fim o cupom seguinte: Caro Leitor, qual é a moça mais bella no seu parecer? É.. Rua... Assignante. ${ }^{38}$

No começo do século XX, ser fisicamente bonita não era o único pré-requisito que tornava uma candidata apta a "ornamentar" com um "retrato" a "primeira página do jornal". Dentro dos códigos sociais da época, era preciso também ser honrada, recatada e bem-educada como o eram moças brancas da alta classe, reverenciadas por competições de simpatia, virtuosismo e elegância promovidas pelo periodismo brasileiro. Mas, dentro das fronteiras de um processo de racialização em curso, ${ }^{39}$ os certames de beleza negra guardavam um intento peculiar: o "reerguimento geral da classe dos homens de cor" ${ }^{\text {"40 }}$ através da revitalização da imagem feminina negra, conforme sugere um segundo concurso.

Realizado na década seguinte pelo Getulino, desta vez, além da

\footnotetext{
${ }^{38}$ FBN-CPM, "Concurso de Belleza", O Menelick, 1 de janeiro de 1916, anno 1, n. 3, p. 4.

39 Importantes discussões que relacionam à desarticulação da escravidão a um crescente processo de racialização encontram-se em Wlamyra R. Albuquerque, $O$ jogo da dissimulação: abolição e cidadania negra no Brasil, São Paulo: Companhia das Letras, 2009.

40 FBN-CPM, O Bandeirante, São Paulo, de 1918, anno 1, n.3, p. 1.
} 
longa lista de predicados comportamentais requeridos, esperava-se que as concorrentes negras de Campinas estivessem aptas a cumprir a seguinte missão: "manter viva a memória sacrossanta" dos "antepassados (...) que reagiram com próprio sangue" e plantaram "a semente da árvore, cujo fruto hoje colhemos", como bem resumiu Laís de Moraes. Carinhosamente chamada pelos amigos de "Lally", a senhorita, autora da citação, era "um typo de creatura fina e distincta", com "intelligencia aguda e clara" e por isso teve sua fotografia estampada na primeira página, sendo aclamada pelo veículo como a merecedora ao título do referido "concurso de belleza" de $1923 .^{41}$

Provavelmente inspirados por debates e quiçá por revistas femininas anteriores que circulavam pela pauliceia com os propósitos de "estabelecer entre as brazileiras uma sympathia espiritual pela comunhão das mesmas ideias" ${ }^{2}$ e de criticar "o estiolamento moral (...) e a decadência de costumes com base na educação moral e religiosa do povo" ${ }^{43}$, Deocleciano Nascimento do Menelik, Lino Guedes do Getulino e demais companheiros da "classe dos homens de cor" sintonizavam-se com os projetos da época, voltados para a construção de novas representações para o feminino. ${ }^{44}$ Desse modo, ao atuarem como representantes da raça negra, com tais iniciativas e discursos focalizados no feminino, semeavam entre os seus ideias que conectavam gênero e raça, tentando provar que as mulheres negras da classe, distantes das "imagens con-

${ }^{41}$ FBN-CPM, "Questionário", Getulino, 13 de outubro de 1923, anno 1, n. 12, pp. 1-2, p. 1.

${ }^{42}$ FBN-CPD, Presciliana Duarte de Almeida, "Duas Palavras", A Mensageira: Frevista Literaria Dedicada À Mulher Brazileira, São Paulo, 15 de outubro de 1897, anno 1, n. 1, pp. 1-2, p. 1.

43 Álbum das Meninas, revista literária e educativa dedicada às jovens brasileiras, São Paulo, 30 de abril de 1898, ano 1, n. 1, apud Ana Luiza Martins, "Nova mulher...", p. 383.

44 Entre os anos 1890 e 1930, diferentes grupos dedicaram-se a pensar novas representações para as mulheres, representações estas condizentes com a modernidade e cosmopolitanismo. Para o Brasil, ver, dentre outros: Maria Martha de Luna Freire, Mulheres, mães e médicos: discurso maternalista no Brasil, Rio de Janeiro: Editora FGV, 2009 e Sueann Caulfield, Em defesa da honra. Para os EUA, ver, por exemplo, o livro de Martha H. Patterson, The American New Women Revisited: A Reader, 1894-1930, Rutgers: The State University, 2008 e as seguintes discussões da imprensa negra e judáica da época: John Adams Jr., "Rough Sketches: A Study of the Features of the New Negro Women", The Voice of the Negro, v. 1, n. 8 (1904), pp. 323-26 e Rev. Ella E. Bartlet, "The New Woman", American Jewess: A Monthly Magazine of Social, Literary and Religious Subjects (1895), pp. 169-71. Debates similares na sociedade japonesa do período entreguerras são apresentados por: Barbara Sato, The New Japanese Woman: Modernity, Media and Women in Interwar Japan (Asia-Pacific: Culture, Politics and Society, Durham: Duke University Press, 2003. 
troladas"45, estavam tão prontas para serem células mães da nação como Josephina Alvares de Azevedo, Georgina Teixeira e Julia da Silva, "senhoras [brancas] que trabalhavam na República das Letras". ${ }^{46}$

Nesse jogo de representações, o mundo letrado branco trazia referenciais importantes como as distintas escritoras de A Mensageira, "mulheres brazileiras" ${ }^{\prime 7}$ que, com suas "diáfanas mãos femininas" 48 , teceram centenas de páginas de revistas, folhetins, romances e poesias no começo do século XX. ${ }^{49}$ Ao mesmo tempo, evidenciando políticas e intervenções masculinas no tocante à mulher e ao seu comportamento, outros magazines fundados por homens, tais como $O$ Ramilhete $^{50}$ - e seus conselhos para o "belo sexo" - e Vida Doméstica - recheada com princípios de "limpeza moral"51 para famílias e lares -, não devem ser descartados do hall de inspirações dos jornalistas de cor. Criada no Rio de Janeiro, em 1920, pelo repórter fotográfico Jesus Gonçalves Fidalgo, esta última, aliás, fazia questão de frisar, três décadas depois do lançamento, que seu conteúdo poderia ser "manuseado por qualquer "mocinha, sem censura prévia". ${ }^{2}$

Em meio a tal atmosfera, num esforço de universalização do gêne-

${ }^{45}$ Uma reconstituição histórica das articulações entre gênero, corpo e raça na produção de "imagens controladas" para as mulheres negras encontra-se em: Patricia Hill Collins, The Black Feminist Thought: Knowledge, Consciousness, and the Politics of Empowerment, Nova York e Londres: Routledge, 2009. [ $1^{\text {a }}$ ed. 2000]. Por meio das "imagens controladas", a autora considera que retratar afro-americanas como mammies, matriarcas e amantes quentes justifica a opressão da mulher negra nos EUA, portanto, para ela, romper com tais "imagens", designadas para apresentar racismo, sexismo, pobreza e outras formas de injustiça social como naturais, normais e inevitáveis, tem sido um dos maiores objetivos do pensamento feminista negro. Ao trabalhar numa perspectiva de história atlântica, seus apontamentos tornam-se úteis para investigar as experiências de mulheres de cor no Brasil e nas Américas.

${ }^{46}$ FBN-CPD, Presciliana Duarte de Almeida, "Duas Palavras", A mensageira, p. 1.

47 FBN-CPD, Presciliana Duarte de Almeida, "Duas Palavras", A mensageira, p. 1.

48 Júlia Lopes de Almeida, Jornadas do meu pai, Rio de Janeiro: Francisco Alves, 1920, p. 215.

49 A respeito das escritoras da imprensa feminina no começo do século XX, ver Maria de Lourdes Eleutério, Mulheres escritoras (Tese de Doutorado, Universidade de São Paulo, 1985); Dulcília Buitoni, Mulheres de papel. Representação de mulheres pela imprensa feminina brasileira, São Paulo: Loyola, 1981.

50 O Ramilhete: órgão dedicado ao belo sexo. Este periódico foi fundado em 1901 na cidade de São Paulo e pertencia a Alfredo Durval e Silva e Antônio Correa. Cf. Ana Martins, "Nova mulher", p. 376.

51 FBN-Obras Raras (doravante OR), "Como se faz uma revista. A propósito do aniversário de Vida Doméstica", Vida Doméstica, Rio de Janeiro, mar. 1932, s/p.

52 FBN-OR, "A Sucursal de Vida Doméstica em São Paulo festejou o $33^{\circ}$ aniversário desta revista”, Vida Doméstica, abr. 1953, p. 30. 
ro feminino, mediado por uma noção positiva da raça negra e pelo diálogo com publicações editadas tanto por homens quanto por mulheres da elite branca, os textos e colunas da imprensa negra reúnem um grupo seleto de mães, esposas, donas de casa, trabalhadoras e consumidoras que eram, com muito orgulho, adjetivadas com as categorias "negra" e "de cor". Todavia, revelando os sentidos múltiplos que a cor assumia e as diferenças encobertas na homogeneidade do termo "mulher de cor", percebe-se que as taxonomias também podiam ser acionadas pela comunidade jornalística negra para criticar certos comportamentos, como o das "pretas" que o "Grupo dos XX" recusava que tomassem "parte no próximo baile", 53 ou para enaltecer um padrão de beleza mestiço, como no caso contado pelo Clarim d'Alvorada das "moreninhas alegres lavadeiras", "jovens simples", que "labutando sempre" cantarolavam "cantigas sentimentais" na "estrada empoeirada do Ibá". 54

Nesse contexto de revitalização imagética, ancorado no trabalho como símbolo de "honra" 55 para "rapazes e moças de cor", ao pensar em apropriações distintas para a beleza branca e negra, é interessante reler o trecho do Menelik sobre o concurso de beleza que abre a presente seção e perceber que, embora não identifique a raça, o jornal fazia questão de falar em "beleza feminina" para um público que, ao que tudo indica, era majoritariamente composto pelo segmento de cor. Ao menos do ponto de vista discursivo, a beleza era vista por eles como uma característica absolutamente possível de ser atribuída às leitoras do jornal.

Em contraponto aos estereótipos de feiúra, animalização e hipersexualidade criados e recriados durante e depois da escravidão em torno do seu $\operatorname{corpo}^{57}$, a publicação concentrava seus esforços na produção

53 FBN-CPM, "Será possível”, coluna "Críticas", A Liberdade, São Paulo, 29/12/1919, n. 10, p. 5.

54 FBN-CPM, Moysés Cintra, “As lavadeiras”, O Clarim d'Alvorada, 27 de dezembro de 1925, anno II, n. 17, p. 3.

55 Todos os jornais negros ressaltavam o trabalho como algo digno e indispensável para o levantamento da raça negra, conforme explicitado por esta citação: "trabalho é honra para nós todos e [para] quem saiba viver honradamente". FBN-CPM, "Furto", A liberdade, São Paulo, 29 de dezembro de 1919 , n. 10, p. 3.

56 Manoel de Oliveira Marcondes, "Sapato-Tenis", FBN-CPM, "Furto", A liberdade, São Paulo, 29 de dezembro de 1919 , n. 10, p. 2.

57 A respeito dos estereótipos destinados às mulheres negras ver: K. Sue Jewell, From Mammy to Miss America and Beyond: Cultural Images and the Shaping of US Social Policy, Londres / Nova York: Routledge, 1993. 
imagética de uma "nova mulher negra", bonita, moderna e urbana e, portanto, condizente com a República. ${ }^{58}$ Todavia, nem tudo era tão "transgressor" no Menelik. Em termos de análise do discurso, "Concurso de Belleza Feminina" indica papéis de gênero delimitados dentro de uma perspectiva cunhada nos mesmos moldes do falocentrismo presente na imprensa afro-americana. Na referida nota, "O Menelik" inicia o diálogo na condição de proponente, e a "beleza feminina", escrita no original com letra minúscula, é quem recebe as pomposas desculpas. Por mais que uma leitura superficial, presa apenas aos supostos aspectos positivos da exaltação, leve-nos a pensar que as mulheres estavam com a "bola cheia", outra interpretação revela que o masculino ("O Menelik") discursava para um sujeito passivo, a "beleza feminina". Tal modelo de interlocução conferia pouco espaço para que as leitoras expressassem seu protagonismo.

A importância conferida ao feminino através de espaços específicos como as notas "Leitoras" e "Concurso de Belleza Feminina" não ficou circunscrita ao terceiro número. O primeiro exemplar do jornal já apresentava um espaço intitulado "Leitoras" no qual se lia o seguinte aviso: "O Menelik apresenta-se a vos, na convicção plena que será bem acolhido por todos". ${ }^{59}$ Observa-se que, embora o texto supostamente voltado para um público geral, era anunciado pelo cabeçalho "Leitoras". ${ }^{60}$

Na edição de janeiro de 1916, "Leitoras" II retorna e acima do seu texto passamos os olhos nos seguintes dizeres: "Salve! Salve! Salve 1916! Gentis leitoras e leitores O "Menelick" deseja-lhes Boas Festas e que em vossos lábios só hajam risos de alegria e felicidades durante o decorrer de 1916! Salve 1 de janeiro de 1916! SALVE!". ${ }^{61}$ O redator (é

58 Tal preocupação não ficou restrita à comunidade negra. Os debates sobre a emergência da "nova mulher" tomaram conta do periodismo na virada do século XIX para o XX, tanto no Brasil quanto nos EUA e no Japão. Ver a este respeito: Anna Luiza Martins, "A produção de uma nova mulher: revistas femininas", Martha H Patterson, The American New Women Revisited; Barbara Hamill Sato, The New Japanese Woman.

59 FBN-CPM, "Leitoras", O Menelik, 17 de outubro de 1915, anno 1, n. 1, p. 1.

${ }^{60}$ Para evitar confusões chamarei de "Leitoras" I a nota publicada na edição de 17 de outubro de 1915 e de "Leitoras" II, aquela presente no número 3 do Menelik, publicado em $1^{0}$ de janeiro de 1916.

${ }^{61}$ FBN-CPM, "Salve! Salve! Salve 1916!", O Menelick, 1 de janeiro de 1916, anno 1, n. 3, p. 1. 
possível pensar redatora?) da saudação é deveras cuidadoso ao endereçála a dois públicos que, embora iguais na gentileza, fossem distintos no gênero: "leitoras e leitores". Nesse sentido, também não passa despercebido seu cavalheirismo de incluir primeiro as damas no cabeçalho: "Gentis leitoras e leitores".

Ainda que seja difícil mesurar o papel que as mulheres efetivamente desempenhavam na folha, a evocação das "leitoras" nos dois exemplares analisados sugere que, em vez de uma nota isolada, podemos estar diante de uma coluna dedicada ao público feminino. Assim como no pedido de desculpas pelo atraso do segundo número (que, curiosamente, é impresso como o "n.3"), deparamos-nos novamente com um tipo de texto que parece buscar a aprovação feminina, o que, dentro de um cenário ambíguo, reforça nosso argumento da importância da comunidade feminina para o periódico.

\section{Os homens da classe e as novas mulheres negras do Menelik}

Deocleciano Nascimento e seus companheiros tinham uma preocupação recorrente em agradar e render homenagens às suas "leitoras". Na falta de maiores dados biográficos, a possibilidade colocada para o presente texto é problematizar as mulheres enquanto um grupo no interior da folha. Nesse sentido, diante do seu papel preponderante no jornal, resta perguntar: seriam elas parte de um "grupo de prestígio", ${ }^{62}$ como as "elites de cor" estudadas por Azevedo em Salvador nos anos 1950, ou estariam sendo alvo de políticas de domesticidade" ${ }^{63}$ empreendidas por homens que associavam família e feminino como naturais? Menos do que se posicionar às pressas num dos lados da moeda, é fundamental perceber os elementos de tensão presentes nas representações femininas (e masculinas) do jornal, considerando para isso o caráter relacional e contrastante

${ }^{62}$ Thales de Azevedo, As elites de cor numa cidade brasileira: um estudo sobre a ascensão social e classes socais e grupo de prestígio, Salvador: EDUFBA, 1996.

${ }^{63}$ Sobre "construções de domesticidade", gênero, raça e trabalho doméstico no pós-emancipação no Brasil ver: Olívia Maria Gomes da Cunha, "Criadas para servir: domesticidade, intimidade e retribuição", in Olívia Maria Gomes da Cunha e Flávio dos Santos Gomes (orgs.), Quase-cidadão: histórias e antropologias da pós-emancipação no Brasil (Rio de Janeiro: Fundação Getúlio Vargas, 2007), pp. 377-417. 
das identidades. Para isso, examinaremos outros momentos nos quais nossas personagens foram registradas pela pena dos jornalistas.

Além dos textos acima comentados, os dois números traziam em destaque, bem no centro da primeira página, poesias dedicadas a figuras femininas. Consta na edição de estreia do jornal, a poesia Regosijo, assinada pelo já citado Deocleciano. Nela, o jornalista mostra todo o seu respeito à "Exma. Sra. D. Maria José de Almeida", presidente do Club 13 de Maio de S. Paulo. O fato de o redator-chefe da folha considerar a dama uma "distincta oradora" ${ }^{64}$ fornece mais pistas para compreender melhor o tipo de mulher que a classe considerava mercedora de louvores.

Tanto o pedido de desculpas da nota "Leitoras" quanto a homenagem à presidente do Grêmio e o discurso de Laly, a Miss Getulino de 1923, convergem para a construção imagética de novas mulheres negras, personagens instruídas, capazes tanto de representar sua comunidade quanto de expressar seus anseios através do discurso. Nesse contexto, o poder masculino da escolha ocupa uma dimensão importante, se considerarmos que falamos aqui de mulheres que sofreram a ação de serem selecionadas para constar na folha enquanto personagens que ilustravam uma série de expectativas da "classe dos homens de cor" em torno de idealizações femininas, tais como as de mãe, estudante, miss, oradora, poetisa.

Nesse cenário de representações múltiplas, levando em conta a riqueza de detalhes em cada uma das edições do Menelik (assim como de outros títulos da imprensa negra), aposto na possibilidade de cruzar suas diferentes seções para captar, ao máximo, os padrões femininos que suas páginas procuram criar. Em termos de pesquisa, a iniciativa almeja dar um passo a mais na análise do material uma vez que, em linhas gerais, a historiografia temática empreendeu pouco esforço em estabelecer conexões entre diferentes seções de cada periódico a fim de esmiuçar seus pequenos detalhes. Em vez disso, embasados por uma pouco problematizada ideia de "imprensa negra" ${ }^{65}$, os trabalhos ocupa-

${ }^{64}$ FBN-CPM, Deocleciano Nascimento, Regosijo, O Menelick, 17 de outubro de 1915, anno 1, n. 1 , p. 1.

65 Miriam Nicolau Ferrara, A imprensa negra paulista 1915-1963 (Dissertação de Mestrado, Universidade de São Paulo, 1981); Elisa Larkin Nascimento, O sortilégio da cor: identidade, raça e 
ram-se mais em analisar características "macro" de tal imprensa, tais como acesso à educação, mercado de trabalho, identidade nacional, desconsiderando personagens e conflitos múltiplos. ${ }^{66}$

Ao manter a ideia de colocar em diálogo diferentes seções do Menelik, é interessante considerar a nota "Leitoras" II em conjunto com a poesia Regosijo, transcrita abaixo:

São dias tão felizes, repletos de venturas,

Esses que vos leva de glórias rodeada,

Porque sois vós a mais gentil e admirada

Do quadro juvenil das mais lindas criaturas

Nas festas, certo é das tantas formosuras,

A voz da oradora a ti é confiada;

E ouve-se ela tenra, suave, denodada

Que de tu'alma vem guiadas de recturas

No meio da palavra que tu'alma salta,

As vozes - muito bem - do auditório, aparta

A tua que é sonora, meiga e primorosa!

Sempre no final da tua oração

Ouve-se profunda e longa ovação

De palmas que dá glória a ti que és talentosa. ${ }^{67}$

gênero no Brasil, São Paulo: Sammus, 2003; José Geraldo Marques, "Imprensa e resistência negra: o projeto integracionista em discursos do Getulino" (Tese de Doutorado, Universidade Estadual de Campinas, 2008), http://libdigi.unicamp.br/document/?code=vtls000439486, acessado em: 06/11/2009.

${ }_{66}$ Trabalhos que apresentam direções distintas de tal crítica encontram-se em: Flávio dos Santos Gomes, Negros e política (1888-1937), Rio de Janeiro: Jorge Zahar, 2005; Ana Maria Fagundes e Flávio dos Santos Gomes, "Por uma "anthologia dos negros modernos": notas sobre cultura política e memória nas primeiras décadas republicanas”, Revista Universidade Rural: Série Ciências Humanas, v. 29, n. 2 (2007), pp. 72-88; Paulina Alberto, Terms of Inclusion; Petrônio José Domingues, A nova abolição, São Paulo: Selo Negro, 2008; Rodrigo Miranda, Um caminho de suor e letras: a militância negra em Campinas e a construção de uma comunidade imaginada nas páginas do Getulino (Campinas, 1923-1926) (Dissertação de Mestrado, Universidade Estadual de Campinas, 2005); Micol Seigel, The point of comparison: Transnational Racial Construction, Brazil and the United States, 1918-1933 (Tese de Doutorado, New York University, 2001).

${ }^{67}$ FBN-CPM, Deocleciano Nascimento, Regosijo, O Menelik, 17 de outubro de 1915, anno 1, n. 1 , p. 1. 
É de fácil percepção o fato de que os dois textos esforçam-se sobremaneira em exaltar a mulher, no entanto, tal exaltação ocorre de formas distintas. Na nota "Leitoras" II, a figura feminina é reverenciada na condição específica de leitora; leitora que de tão especial merece novidades vindas do céu. De novo, caberia aos homens a árdua missão de buscar notícias nas estrelas, ou seja, informações que fossem dignas de ocupar "mãos delicadas", que por serem o "berço gentil" da alma saberiam esperar pacientemente.

Esta função estritamente masculina de fornecer informações fica reforçada pela já apresentada lista de fundadores do jornal, divulgada na edição inaugural de outubro de 1915 e composta exclusivamente por homens. Já no tocante à poesia, a mulher homenageada ocupa o lugar específico de oradora, função muito comum no meio negro da época. ${ }^{68}$ Se a historiografia temática já reconheceu a importância de oradores como o patrionovista Arlindo Veiga dos Santos e o "tribuno popular" Vicente Ferreira ${ }^{69}$, o mesmo comentário não se estende ao caso feminino. Quase três décadas depois da publicação de $O$ Menelik, por exemplo, oradoras como Silvia de Oliveira, Sebastiana Vieira e Benedita da Costa contagiarão frentenegrinos com suas exímias oratórias nos túmulos de abolicionistas durante as festividades do 13 de maio. ${ }^{70}$ Sua presença assim como a de outras militantes contrasta com a pouca preocupação historiográfica de investigar a participação feminina nesta imprensa. ${ }^{71}$

Regosijo também dá pistas para refletirmos sobre as imagens enaltecidas pelos organizadores de $O$ Menelik. Se, em "Leitoras" II, ser alfabetizada representava um importante traço distintivo, na poesia será a vez do poder de oratória ser louvado. Assim, ao juntar os indícios anteriores à homenagem rendida à presidenta do Club 13 de Maio, en-

${ }^{68}$ Quanto ao papel dos oradores nos movimentos negros da época ver o depoimento de Raul Joviano do Amaral, ex-tesoureiro da Frente Negra Brasileira. Miriam Ferrara, A imprensa negra paulista 1915-1963 (Dissertação de Mestrado, Universidade de São Paulo, 1981), p. 84.

${ }^{69}$ Para um texto de época a respeito da trajetória de Vicente Ferreira no meio negro, ver, dentre outros: Gervásio de Moraes, "Um idolo que fala", O Clarim d'Alvorada, 4 de março de 1928, anno I, n. 2, p. 1.

70 FBN-CPM, A Voz da Raça, 20 de maio de 1933, anno 1, n. 3, p. 2.

71 Uma contribuição que faz exceção a esta regra está em Petrônio Domingues, "Frentenegrinas: notas de um capítulo da participação feminina na história da luta anti-racista no Brasil", Cadernos Pagu, v. 1, n. 28 (2007), pp. 345-74. 
tendemos melhor o protótipo feminino das mulheres instruídas. Cultuadas pelo jornal, tais figuras deveriam ser capazes de servir como exemplos de civilidade. Em meio à construção de novas mulheres negras, vale notar que até aqui nenhum dos dois textos fazia exigências quanto à capacidade de escrita das mulheres, tarefa, à primeira vista, restrita ao universo masculino como, a princípio, delimitava o próprio cabeçalho do jornal - "dedicado aos homens de cor".

Poderíamos nos deixar levar pelo caminho mais óbvio de considerar que $O$ Menelik enquadrava-se no que postulavam os códigos culturais da época acerca da mulher higienizada e de sua vinculação específica ao âmbito privado. ${ }^{72} \mathrm{E}$ esse último aspecto, inclusive, poderia ser ratificado pela fala de Júlia Lopes de Almeida sobre a "inaptidão" feminina para as artimanhas da escrita:

Nós, as mulheres, não temos sempre facilidade de bem exprimir os sentimentos por palavras; eles parecem-nos por demais sutis e complexos; elas insuficientes e fraquíssimas. Dizem que há para todas as coisas expressões precisas, de inquestionável exatidão; a língua modula no som, e inalterada, a essência da mais rara alegria ou do mais terrível desespero. Mas essa é a interpretação dos fortes; a nossa dilui-se, numa gota incolor e inodora, que é como um chuvisqueiro em uma rosa, se nasce da alegria; ou, se vem da dor, como um floco de neve em uma brasa, que apaga a luz e deixa a nu o carvão. ${ }^{73}$

Tal caminho teria algum sentido não fosse o já conhecido papel de conciliadora de Júlia Lopes de Almeida. A condição daquela "que harmonizara companheirismo e organização, rebeldia e luta - com o papel de mãe e esposa"74 torna possível considerar que, assim como ela, as mulheres do meio negro também procuraram seus próprios caminhos conciliadores. Nesse sentido, se assumirem ou serem identificadas ape-

72 Ver dentre outras: Adriana Dantas Reis, Cora: lições de comportamento feminino na Bahia do século XIX, Salvador: Centro de Estudos Baianos da UFBA, 2000.

73 Júlia Lopes de Almeida, Livros das donas e donzellas, Rio de Janeiro: Francisco Alves e Cia, 1906, p. 1.

74 Rachel Soihet, "Comparando escritos: Júlia Lopes de Almeida e Carmem Dolores", Caderno Espaço Feminino, Revista do Núcleo de Estudos de Gênero e Pesquisa sobre a Mulher, v. 9, n. 10-1 (2001-2002), pp. 85-107. 
nas como leitoras ou oradoras (de discursos supostamente redigidos por homens) poderia ser uma forma de isentá-las de serem tachadas de loucas, conforme acontecia com muitas daquelas que "ousaram revelar alguma criatividade". ${ }^{75}$

A despeito dos riscos que o papel de escritora trazia, o reconhecimento público da mulher no desempenho de tal função esteve presente na seção "Caixa-Balaio". Lá, D. Leopoldina fica sabendo que o soneto que enviara para a redação do jornal "está em análise" e, a seguir, D. Ignez do Amaral é nomeada "colaboradora efetiva no ramo de versos da ordem de Pé Quebrado". 76 A convocação abaixo, retirada da coluna "Noticiário" desemboca em mais um espaço pelo qual o jornal procurava articular gênero e raça por intermédio da figura da escritora: "o próximo número d' 'O Menelick' será colaborado por pensamentos femininos, por isso gentis leitoras, não poupem esforços e enviem-nos os vossos trabalhos". ${ }^{77}$

Apesar de não termos como saber quem de fato escreveu no próximo número, até o presente momento não localizado, novamente, somos confrontados com um texto no qual a presença feminina no periódico é representada como algo singular, honroso e essencial; algo, literalmente, digno de nota. Desse modo, os dois momentos acima marcam uma curiosa passagem na construção imagética do feminino no jornal, pois a mulher é promovida da condição de leitora àquela de escritora, confirmando que suas habilidades eram realmente completas.

Como leitora ou escritora, de um jeito ou de outro, todas as trilhas do Menelik conduzem ao papel das mulheres de cor instruídas como criaturas excepcionais. A maneira com que Mademoissele F. Pinheiro é retratada na poesia de Deocleciano Nascimento, por exemplo, reforça tal singularidade. Destarte, a representação - "alma santa", "voz sonora", "gentil" e "admirada" como a "mais linda criatura" - sugere que existia um grupo de mulheres incríveis, alçadas ao posto de musas do jornal. Gentis, pacientes e sorridentes, almas santas...

75 Constância Lima Duarte, "O cânone literário e a autoria feminina", in Neuma Aguiar (org.), Gênero e ciências humanas: desafio às ciências desde a perspectiva das mulheres, Rio de Janeiro: Rosa dos Tempos, 1997, pp. 85-94, p. 88.

76 FBN-CPM, D'eoclé, “Caixa-Balaio", O Menelik, 17 de outubro de 1915, anno 1, n. 1, p. 3.

77 FBN-CPM, O Menelik, 1 de janeiro de 1916, anno 1, n. 3, p. 3. 
Afinal, quem seriam nossas especiais? Se observarmos os índices de analfabetismo entre a população negra da época, podemos pensar que sua condição de leitoras e escritoras é um traço determinante para torná-las assim tão singulares. ${ }^{78}$ Nesse caso, cruzando gênero e raça, menos do que um substantivo, o vocábulo leitora, disseminado nas duas edições do Menelik, assume o papel de adjetivo porque - ainda que implicitamente - qualifica a mulher negra como instruída.

\section{Duque e suas “distinctas" escritoras}

"Caixa-Balaio" não foi o primeiro espaço no qual o Menelik mencionou diretamente suas escritoras. Numa curiosa seção denominada "Idéias Parafuzadas" ${ }^{79} \mathrm{o}$ já citado Duque informava a Izaurinha e Brasilia que "aguarda[va] ser correspondido com a contribuição de cada uma". Chama a atenção que tal convite não tenha sido feito sem que antes o escritor cumprimentasse as senhoritas por serem "distintas e inteligentes normalistas". A menção à condição de estudante das jovens também ajuda a pensar que tipo de participação feminina era requisitada pelo veículo. Estaríamos diante de uma elite feminina negra letrada? Mencionar a posição das senhoritas poderia ser uma estratégia para garantir credibilidade ao jornal, capaz de ultrapassar as fronteiras do meio negro?

A mesma seção também destinava espaço para citar aquelas escritoras acometidas pela fraca memória, como Paulina da Rocha e Angelina Pinto, que deixavam de cumprir promessas feitas outrora, rendendo assim um provocativo "estou de mal" do nosso editor. Entretanto, a dupla de senhoritas não tinha com o que verdadeiramente se preo-

${ }^{78}$ Os recenseamentos de 1910 e 1930 não apresentaram dados sobre alfabetização. Considerando uma população nacional de 41.236.000 habitantes (brancos - 63,5\%; pardos - 21,2\%; pretos $-14,6 \%$; outros $-0,7 \%$ ), o Censo de 1940 indicou para os brasileiros com idade superior a dez anos os seguintes índices de alfabetizados: brancos - 52,8\%; pardos - 29,3\%; pretos - 20,9\%, in George Reid Andrews, "Racial Inequality in Brazil and the United States: A Statical Comparison", Journal of Social History, v. 26, n. 2 (1992), pp. 229-63, p. 244. Cf. também "População Presente", Tabela Resultados dos Recenseamentos Demográficos, 18721950, in O Brasil em números (Resultados dos Recenseamentos Demográficos 1872-1950), Serviço Nacional de Recenseamento, p. 8. Disponível em: http://www.ibge.gov.br/seculoxx/ arquivos_pdf/populacao/1960/populacao1960bn_02.pdf Acesso: 07/10/2011.

79 FBN-CPM, Duque, "Idéias Parafuzadas", O Menelik, 17 de outubro de 1915, anno 1, n. 1, p. 3. 
cupar. O malcriado Duque fazia questão de não deixar mal entendidos: "as pazes serão feitas quando eu receber as promessas". ${ }^{80}$ Podemos pensar que o conteúdo de seu texto justificaria o uso de um pseudônimo, visto que o redator não dispensa os puxões de orelha nas duas citadas moças? Ao publicar nome e sobrenome das senhoritas, cobrando-lhes o que supostamente lhe fora prometido, Duque parece estar bem à vontade para se fazer valer do dito popular "promessa é dívida". Mas o que significaria ter seu nome estampado no jornal como uma escritora inadimplente? Para quem esse tipo de informação era relevante, ou mesmo vexatória? Tal exposição teria sentidos diferentes para homens e mulheres citados?

Observador atento de suas escritoras e leitoras, o jornalista parecia também não se sentir intimidado pelas "mais velhas". Sem perdões, ele aproveitou o espaço que lhe destinaram no centro da terceira página para mais uma bronca. Dessa vez, a vítima escolhida era D. Emília Cardozo. Embora sem papas na língua, devemos ser justos e frisar que Duque proferia suas repreensões dentro do mais perfeito cavalheirismo: "Leia, faça o obséquio "O Menelik", na próxima tiragem, sim!" 81 De novo, o fato de cinco mulheres serem diretamente citadas pelo jornal, sendo que quatro delas já requisitadas na sua primeira edição para oferecerem contribuições, evidencia que as quatro senhoritas e a solitária senhora D. Emília participaram, em alguma medida, de espaços de organização prévia do Menelik.

Apesar de ausentes da lista de criadores do periódico, teriam as cinco escritoras participado da reunião dos fundadores ocorrida em 18 de julho de 1915? Em caso negativo, onde o convite para colaborar com o periódico fora feito? Embora no momento não seja capaz de encontrar respostas precisas a tais perguntas, fica o indício de que essas mulheres foram escolhidas para de alguma forma participar da "Sociedade Jornalística de O Menelik". Mais que isso, na reconhecida posição de escritoras, elas receberam convites para publicar suas contribuiçõos, justamente na edição inaugural do jornal. Faz então sentido pensar que

${ }^{80}$ Duque, "Idéias Parafuzadas", O Menelik, 17 de outubro de 1915, anno 1, n. 1, p. 3.

81 Duque, "Idéias Parafuzadas", O Menelik, 17 de outubro de 1915, anno 1, n. 1, p. 3. 
a condição feminina de receptora, presente na maior parte das narrativas nas quais as mulheres aparecem como sujeitos (passivos), pode representar uma estratégia dos redatores para subtrair a importância do feminino para o jornal. Nesse rastro, teriam Izaurinha e Brasilia deixado de publicar seus textos devido a desavenças internas, levando Duque a protestar por meio de sua imperdoável pena?

Ao considerar as quatro páginas, totalmente ocupadas da edição de estreia, nota-se que a falta de colaboradores não era um problema. Então, por que um jornal "dedicado aos homens de cor" reivindicava tão efusiva e insistentemente a participação feminina? Ao persistir na proposta de uma análise historiográfica que priorize gênero e raça, enfatizo que os ecos da narrativa de Duque vão ainda mais além. Seu texto na íntegra, quando cruzado aos dados numéricos de gênero, reforça a hipótese do protagonismo feminino no jornal. Dos sete homens citados pelo redator apenas um, o acanhado "seu Antônio", foi convidado a publicar seus "sentimentos" na forma de poesia. Para os demais, como o "Ilmo Sr. Tatú Canastra", o redator não reserva convites, mas apenas saudações e votos de amizade.

Ao considerar os ideais de feminilidade que circulavam à época, é curioso observar uma espécie de construção de gênero às avessas na seção assinada por Duque, na qual as mulheres seriam as escritoras e os homens os amigos. Tal inversão revela o brilhantismo intelectual das leitoras do Menelik ou encobre conflitos internos de gênero? Outra dimensão importante que se articula a de gênero na narrativa do jornal é aquela da faixa etária feminina. Observa-se uma maioria de apelos voltados para as "senhoritas" em contraposição a um único dirigido a uma "senhora".

As expectativas depositadas na "mocidade negra" 82 para o futuro dos descendentes da escravidão foi um tema recorrente em diferentes jornais de cor. Nesse sentido, os jovens seriam seu público-alvo ou, pelo menos, era importante ter tal segmento como simpatizante e, es-

\footnotetext{
${ }^{82}$ A expressão "mocidade negra" aparece, dentre outras, em: FBN-CPM, Leite, "Devemos fazer a nossa Sociedade Cooperadora para o Levantamento da Raça", $O$ Clarim d'Alvorada, 26 de julho de 1931, ano 8, n. 34, p. 1.
} 
pecialmente, como colaborador. Mais uma vez, as mulheres preponderam, se considerarmos que apenas o Sr. Antônio é convidado a colaborar. Afinal, onde estavam os rapazes "da classe"? Diante da totalidade de cargos preenchida por homens, seria importante convidar mulheres que contribuíssem para que o jornal não ficasse restrito ao segmento masculino?

\section{"Concurso de belleza feminina": as "merecedoras de votos"}

Temos visto até aqui a emergência de dois grupos de mulheres no Menelik: leitoras e escritoras. Note-se que o feminino é sempre atrelado à sua faixa etária, expressa por terminologias como: jovens, senhoritas e, com menos recorrência, senhoras. Se em outros momentos do jornal, senhoras e senhoritas poderiam dividir o mesmo holofote, este não é o caso do concurso de beleza, voltado especificamente para as segundas. A lúdica permuta entre "estrelas" e "sorrisos" ou, para ser mais direta, entre masculino e feminino, parecia ser ainda mais sedutora do que se pressupunha.

As "boas novas" para mulheres tão queridas não cessavam. Em $1^{0}$ de janeiro de 1916 , quando da publicação de seu terceiro número, $O$ Menelick deixava saber a seguinte informação:

Abrimos com o presente número um concurso de beleza feminina, cujo concurso será em duas tiragens distribuídas nas seguintes formas: na primeira tiragem, a partir da próxima vindora, daremos uma demonstração geral de todas aquelas que mereceram votos e, na segunda, o resultado final do concurso. Aquela que bater o "record" ornamentará com o seu retrato a primeira página de nosso jornal, caso consinta que nós assim procedemos. N.B. - O concurso é bem entendido, entre a "classe" e os votos devem ser dados pelos homens que forem assinantes, enchendo para este fim o cupom seguinte: Caro Leitor, qual é a moça mais bella no seu parecer? É.. Rua... Assignante. ${ }^{83}$

Um concurso de beleza, que já havíamos conhecido acima, no qual as donas dos "lábios de rosa" poderiam ser dignamente aclamadas. O foco na juventude feminina representa um ponto nevrálgico e seu

83 FBN-CPM, "Concurso de Belleza", O Menelick, 1 de janeiro de 1916, anno 1, n. 3, p. 4. 
ápice repousa num certame para escolher "a moça mais bonita do bairro". ${ }^{84}$ A pequena nota encobre diferentes debates envolvendo gênero, faixa etária, raça e imagem. Inicialmente, é interessante examinar a mudança da terminologia utilizada de "senhorita" para "moça". Tudo indica que o emprego de categorias distintas para qualificar as candidatas extrapolava o quesito idade. Mais do que mera substituição, a escolha do termo moça para nomear aquela mais bonita do bairro incorpora novos tópicos à discussão; tópicos estes relacionados a temas maiores como honra, pudor e moralidade.

Além de senhorita era essencial ser moça. Esta dupla conceitualização conecta-se a projetos e expectativas acerca da honra e da moral que transformam ambas as categorias em adjetivos indissociáveis naquele contexto. Uma consulta a um dicionário de época auxilia a tornar o jogo de palavras mais inteligível. Entre as definições mais corriqueiras do vocábulo "moça" ${ }^{85}$ no começo do século XX, Caldas Aulete registrou "virgem, donzela" e "boa moça". Já para "senhorita" 86 encontramos "solteira" e "moça solteira" além de mais outro sugestivo: "mulher de classe baixa que se dá ares de senhora". Desse modo, para participar do concurso de $O$ Menelik era preciso ser jovem, instruída e virgem. A posse das três características transformava Olga, Malvina, Júlia e quem sabe outras mulheres em merecedoras de votos e, portanto, futuras senhoras da classe de cor.

Através da leitura da nota "Concurso de Belleza", ${ }^{87}$ intersecções entre feminino e masculino começam a se delimitar de forma mais nítida. Um detalhe sem aparente importância é o fato de existir uma lista de candidatas merecedoras de votos exatamente na mesma edição que inaugura o concurso. A relação de nomes - localizada na página anterior a do próprio anúncio do certame - pode sugerir que o mesmo foi aberto (mesmo que por vias informais) antes de ser tornado público pelo jornal. Se tal possibilidade não pode ser de todo descartada, a leitura aten-

\footnotetext{
${ }^{84}$ FBN-CPM, "Concurso de Belleza", O Menelick, 1 de janeiro de 1916, anno 1, n. 3, p. 4.

85 Francisco Júlio de Caldas Aulete, "moça", Caldas Aulete Digital - Dicionário Contemporâneo da Língua Portuguesa, Lexikon, Editora Digital, 2007[1 ${ }^{\mathrm{a}}$ ed. 1881].

${ }^{86}$ Francisco Júlio de Caldas Aulete, "senhorita", Caldas Aulete Digital.

${ }^{87}$ FBN-CPM, "Concurso de Belleza", O Menelick, 1 de janeiro de 1916 , anno 1, n. 3, p. 4.
} 
ta da nota mostra que ao menos os redatores mantiveram coerência com sua proposta: "abrimos com o presente número um concurso de beleza feminina, cujo concurso será distribuído em duas tiragens distribuídas nas seguintes fórmas (...)".

Apesar de os jornalistas considerarem a publicação do jornal como a abertura oficial do concurso, deixavam claro que havia uma etapa prévia de escolha das candidatas e que caberia a eles conduzi-la: "na primeira tiragem a partir da próxima vindoura daremos uma demonstração geral de todas aquelas que mereceram votos". Parece vir daí a explicação para que os nomes de doze concorrentes "merecedoras de votos" já estivessem disponíveis na mesma edição. O texto também sugere papéis de gênero claramente definidos no qual apenas mulheres seriam candidatas "abrimos (...) um concurso de belleza feminina" - e os homens, seus votantes. Entretanto, ser homem não era o critério absoluto.

Para que pudessem dar "seu parecer" sobre a "moça mais bonita do bairro", era necessário que sua condição masculina estivesse acoplada à posição de assinante do jornal: "os votos devem ser dados pelos homens que forem assignantes". A abreviatura "N.B." (Note Bem), direcionada aos leitores parecia reforçar a importância do critério. Não há também nenhuma menção à cor das "merecedoras de votos". À primeira vista parece óbvio que por se tratar de um concurso promovido por um jornal negro apenas candidatas "de cor" poderiam participar, no entanto, a leitura detalhada do texto indica que a cor aparece nas entrelinhas do texto como um critério racial do certame: "o concurso é, bem entendido, entre a classe".

Ainda sobre os bastidores do inspirador certame de beleza, por mais que ainda não tenhamos maiores informações biográficas sobre as senhoritas da lista, a atitude de fazer uma seleção prévia daquelas dignas de serem votadas indica que a competição era um momento chave para veicular mais um tipo de imagem feminina. Ao cruzar a lista a outras partes do jornal, notamos a presença de uma personagem por nós já conhecida: Angelina Pinto, a mesma senhorita que o implacável redator Duque cortara relações por ela não haver lhe entregue a colaboração prometida para o número de estreia do jornal. Assim, é possível conjecturar que o perfil reservado para as candidatas envolvia os papéis de leitora e de escritora. Esperavam assim que a "moça" mais bonita do 
bairro fosse uma jovem de cor instruída, capaz de ler, escrever e de assim representar honrosamente a sua "classe" como fizera Laly, a campeã do certame do campineiro Getulino.

Para ser uma concorrente era necessário ser "merecedora de votos". Isso indica que existiam responsáveis, da mesma forma que critérios, para determinar aquelas que seriam dignas de votação. Creio que havia competidoras que, por algum motivo, não mereciam votos e por isso tiveram seus nomes vetados desta e doutras possíveis futuras listas. A não menção a preferências físicas esperadas também ajuda a pensar que, mais do que aparência, valores e comportamentos eram pré-requisitos fundamentais. Isso, sem dúvida, não seria um caso isolado ou um traço distintivo do meio negro, afinal, no começo do século XX, estavam em voga projetos e debates em torno da construção da nação nos quais a mulher representava uma personagem cabal. Trata-se de uma época em que a família harmoniosa havia sido convertida em metáfora de uma jovem República civilizada que, por sua vez, dependia da mulher para alcançar o seu sucesso. Parece que os membros de $O$ Menelik estavam preocupados em demonstrar a potencialidade do feminino negro dentro de tal projeto nacional-republicano.

\section{As novas mulheres negras e a República}

Homens e mulheres de $O$ Menelik estabeleceram estratégias alternativas à imagem feminina restrita ao domínio privado. Para isso, a equipe do jornal investiu em discursos que possibilitassem que papéis públicos e privados definissem simultaneamente as tipologias femininas construídas nas suas páginas. Leitoras, escritoras, presidentes de clubes e associações ou ainda candidatas de uma competição de beleza bateram de frente com teses médicas que provavam a inferioridade intelectual da mulher, sentenciando-a ao confinamento do lar.

Ao conjugar raça e República em diálogo com imagens literárias que circulavam desde finais do século XIX, tais como a da "filha dedicada" e aquela do "anjo do lar", ${ }^{88}$ a poesia assinada por Roque Rosa transforma a mulher negra numa candidata merecedora não de votos de

${ }^{88}$ Constância Duarte, "O cânone literário" 
beleza, mas do importante título de "mãe republicana". Personagem escolhida para o seu "primeiro trabalho" como poeta, ele assim a retrata:

A única pessoa em quem podemos cegamente confiar sem receio de sermos traídos, porque somos sangue do seu sangue, carne da sua carne. Feliz! Feliz daquele que a sua possui, porque assim pode ouvi-la e seguir-lhe os conselhos. ${ }^{89}$

Os elogios destinados à saudosa mãe do jovem de dezenove anos mostram que existia uma preocupação de construir uma imagem feminina negra que se afinasse com os códigos culturais da época, mas que, ao mesmo tempo, atendesse às necessidades e expectativas do meio negro. Conforme acredito, existiu um esforço expresso em diferentes seções de $O$ Menelik de outorgar às mulheres um lugar de prestígio e destaque no seu interior. Entretanto, tal esforço deve ser pensado não como uma dádiva dos homens às mulheres, mas como um dos resultados de embates de gênero, presentes nos bastidores do jornal.

$\mathrm{Na}$ publicação, existiram iniciativas explícitas não de outorgar no sentido de dar, conceder, mas de fazer ouvir a voz de tais personagens como no referido caso dos convites para a publicação de contribuições femininas. Assim, analisar as imagens femininas que circularam no Menelik como produto de relações conflitivas entre mulheres e homens de cor, é um passo importante para reconstituir histórias do feminino de cor no mundo livre. Ao abrir mão dos consensos e das benesses que os textos sugerem numa leitura superficial, criamos espaço para interpretar tais representações como resultados de mecanismos de pressão levados a cabo por essas personagens.

Tais iniciativas, quando analisadas em conjunto apontam para um projeto de inclusão feminina que procurou se adequar aos padrões da época sem, contudo perder de vista ou apagar as especificidades vivenciadas pelas mulheres negras. A leitura miúda dos dois exemplares do jornal $O$ Menelik demonstra que as palavras "insuficientes e fraquíssimas" com as quais se referiu às mulheres, em 1906, a célebre literata Júlia Lopes não faziam parte do léxico das mulheres da comuni-

89 BN-CPM, Roque Cardoso Rosa, "Mãe”, O Menelick, 1 de janeiro de 1916, anno 1, n. 3, p. 2. 
dade do periódico. Embora ainda permaneçam sujeitas anônimas e, por mais que aparentemente não ocupassem cargos de direção no órgão, nossas gentis senhoras e senhoritas, leitoras, escritoras e candidatas a misses cumpriam os requisitos para atuar como colegas, melhor seria dizer, amigas da classe e mães da jovem nação.

\title{
Texto apresentado em 21/6/2010 e aprovado em 14/2/2012
}

\begin{abstract}
Resumo
Parte da história social do pós-emancipação no Brasil, este artigo analisa as imagens femininas produzidas por jornalistas negros na cidade de São Paulo no começo do século XX. Se pesquisas anteriores apontam para a ausência de mulheres na chamada imprensa negra paulistana, um estudo detalhado de duas edições do jornal O Menelik (1915-1916) evidencia que tal presença é subestimada pela historiografia. É bem verdade que foram raras as ocasiões em que as mulheres apareceram como escritoras. Mas, por outro lado, estas personagens foram retratadas de diferentes maneiras (poesias, contos, críticas comportamentais e concursos de beleza) nas páginas desse e de outros periódicos negros da época. Assim, considerando uma reciprocidade entre público leitor e imagens veiculadas, as menções recorrentes às mulheres de cor são aqui interpretadas como forte indício da sua presença na comunidade do periódico. Ao ter em mente a importância de análises que articulem gênero, raça e imagem no pós-emancipação, a existência de tais representações abrem instigantes caminhos para problematizar a aparente ausência feminina na imprensa negra.
\end{abstract}

Palavras-chave: mulheres negras - beleza - raça - imprensa negra - pós-emancipação

\begin{abstract}
This study examines an aspect of Brazilian social history during the period after Abolition: women's participation in the black press in early twentieth century São Paulo and the contradictions that it suggests. While earlier studies have claimed that women did not play a role in these publications, a detailed study of Menelik, a leading black newspaper from 1915-16, shows that women were extremely involved and that their presence has been underestimated by historians. Although few actually signed their names to articles, women participated in various important ways - contributing poetry, short stories, criticism and beauty contests - to Menelik and other black newspapers of the time. This article thus probes the absence of gender as an analytical tool in post-Abolition historiography, offering suggestions for incorporating perspectives on gender into scholarly work on the black journalism.
\end{abstract}

Keywords: black women - beauty - race - black press - post-Abolition 